\title{
Stochastic Frontier Analysis of the Technical Efficiency of Smallholder Maize Farmers in Central Province, Zambia
}

\author{
Susan Chiona ${ }^{1}$, Thomson Kalinda ${ }^{1}$ \& Gelson Tembo ${ }^{1}$ \\ ${ }^{1}$ Department of Agricultural Economics \& Extension, University of Zambia, Lusaka, Zambia \\ Correspondence: Thomson Kalinda, Department of Agricultural Economics and Extension, University of Zambia, \\ Lusaka, Zambia. Tel: 2609-6645-4366. E-mail: thomsonkalinda@gmail.com
}

Received: July 1, 2014 Accepted: August 4, 2014 Online Published: September 15, 2014

doi:10.5539/jas.v6n10p108 URL: http://dx.doi.org/10.5539/jas.v6n10p108

\begin{abstract}
Maize is the main staple food and cornerstone of Zambia's agricultural economy and as such, high productivity and efficiency in its production are critical to food security and poverty reduction in the country. This paper estimates the technical efficiency of maize producers in Zambia using Stochastic Frontier Analysis (SFA) and also determines the factors which influence technical efficiency in maize production. Primary data from 400 households in the Central Province of Zambia were used in this study. Results show that there exists opportunities to increase technical efficiency from the present level of inputs. The average technical efficiency was at $50 \%$, with a minimum of $2 \%$ and a maximum of $84 \%$. The distribution of the technical efficiency is such that $14 \%$ of the farmers have efficiency scores that are less than $30 \%$ while $46 \%$ of the farmers have technical scores above 50\%, and 14\% have technical efficiency scores above $70 \%$. Maximum likelihood results showed that the age of a farmer, use of certified hybrid seed, access to loans and extension advice and off-farm income influence technical efficiency. The study recommends Government and other maize stakeholders to devise strategies for improving access to credit and extension services and promoting use of certified hybrid seed as a way to improve the technical efficiency of maize producers in Zambia.
\end{abstract}

Keywords: maize, technical efficiency, smallholder stochastic production frontier, Zambia

\section{Introduction and Background}

Maize remains the cornerstone of Zambia's agricultural economy. Currently, maize is Zambia's number one commodity in terms of value, second after sugarcane in production and fourth in exports after sugar, cotton, and tobacco (FAO, 2011). It represents an estimated $41 \%$ of gross farm household income and $33 \%$ of total household crop sales (Jayne et al., 2010). Even though maize is only one of the many grain and root crop staples consumed by the Zambian population, it is overwhelmingly the favored staple food in urban areas. In rural areas it is the main staple food in the central, southern, and eastern parts of the country which happen to be the most densely populated parts of the country. As such, maize is regarded as the most important food item in the Zambian diet (Kumar, 1994).

Maize is grown widely throughout the country with $88 \%$ of all the farming households growing it (CSO, 2006) and its production is dominated by small scale farmers who constitute an important and invaluable component of the Zambian economy. Individually, while not exerting much influence they collectively form an important foundation on which the economy rests. It has been established that they produce about $80 \%$ of the 1.2 million metric tons maize requirement of Zambia. However, the productivity of these maize producers is low. On average, productivity among the small scale farmers ranges between 1.2 and 1.6 tons per hectare against the potential of 5 tons for open pollinated varieties and 10 tons for hybrid varieties (MACO/CSO/FSRP, 2008).

The Government of the Republic of Zambia (GRZ) has appreciated the importance of maize and as such, it is commonly understood that policies to influence maize production and input use on maize constitute the major means by which to promote smallholder income growth and food security. The GRZ has drawn up various policies to support smallholder incomes through maize production and these include producer support prices offered by the Food Reserve Agency (FRA), tariffs on imported maize to restrict inflows of maize that might undercut farm prices, and government programs to make subsidized fertilizer and hybrid seed available to small scale farmers (Zulu et al., 2007). Despite all these efforts, maize yields in Zambia have been stagnant for decades. Studies on subsidized fertilizer beneficiaries have shown that productivity is still stagnant at 2.5 tons per hectare 
(ACF, 2009). The unfortunate fact remains that the majority of Zambia's small farmers still do not produce enough to feed their own families, and very few sell any substantial surplus. An effective economic development strategy depends on critically promoting productivity and output growth particularly among smallholder producers since they make up the bulk of the nation's agricultural population. To achieve this, a study of small-scale maize farmer's present level of efficiency and analysis of factors influencing their level of efficiency is necessary. It will suggest areas of resource use adjustments and allocation required for enhanced productivity as it has been observed that high production and productivity are a direct consequence of efficiency in input use and combination given the prevailing technology (Ogundari \& Ojo, 2008).

Therefore, the main objective of this paper was to estimate the technical efficiency of maize producers in Zambia using Stochastic Frontier Analysis (SFA) and to determine the factors which influence technical efficiency in maize production. Through the estimated model and technical efficiency estimates, some policy implications are suggested to improve maize productivity in Zambia.

\subsection{The Conceptual Framework}

The seminal paper by Farrell (1957) on the measurement of productive efficiency has inspired several studies during the last years on best practice technology and efficiency measures. In this paper, Farrell proposed a stimulating idea to define output of the most efficient firms as the production frontier for all firms as opposed to the neoclassical theory that assumed all firms to be fully efficient in their use of technology. The basic idea underlying the Farrell approach to measuring efficiency is illustrated in Figure 1.

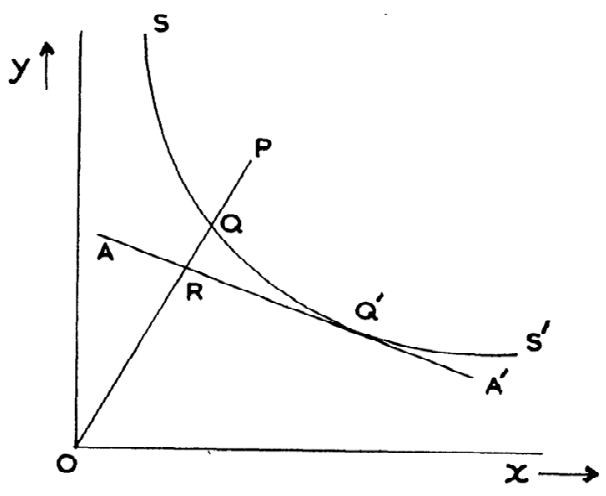

Figure 1. Farrell's measure of technical and allocative efficiency

Source: Ajibefun (2008).

Farrell (1957) considered a firm that employs two factors of production $\mathrm{X}$ and $\mathrm{Y}$ to produce a single product $\mathrm{P}$, under conditions of constant returns to scale. These assumptions make it possible to illustrate the production function by a simple isoquant diagram, designated by SS' in Figure 1. The point $\mathrm{P}$ represents the units of two factors, per unit of output that the firm is observed to use. The isoquant 'SS' represents various combinations of the two factors that a perfectly efficient firm might use to produce a unit output. It is also important to note that 'SS' presents a lower bound of a scatter indicating the same level of output and as such Q and P are on the same isoquant. The point $\mathrm{Q}$ represents an efficient firm using the two factors in the same ratio as $\mathrm{P}$. It can be seen that it produces the same output as $\mathrm{P}$ using only a fraction $\mathrm{OQ} / \mathrm{OP}$ as much of each factor. It is producing $\mathrm{OP} / \mathrm{OQ}$ times as much output from the same inputs. Therefore OQ/OP is defined as the technical efficiency of Firm P. The technical inefficiency of that firm is presented by the distance QP which is the amount by which all inputs could be proportionally reduced without a reduction in outputs. The firm is technically efficient if the ratio is equal to 1 . If the ratio is less than 1 the firm is inefficient. Price or allocative efficiency of the firm can be measured from the same diagram above. This measures the extent to which a firm uses the various factors of production in the best proportions, in view of their prices. Considering the budget line represented by AA', its slope is equal to the ratio of the prices of the two factors of production. Therefore the optimal point is obtained where the isoquant curve is tangential to the budget line and that is point Q'. At this point the firm is both technically and allocativelly efficient. The allocative efficiency is the fraction OR/OQ. 


\subsection{The Stochastic Production Frontier (SPF) Approach}

Following the pioneering work of Farrell various modifications and improvements have been made. Aigner and Chu (1968) translated Farrell's frontier into a production function and later, Aigner et al. (1977), Meeuseen and van den Broeck (1977) and Battese and Corra (1977) suggested the stochastic frontier approach. This approach deals with stochastic noise and permits statistical test of hypothesis pertaining to production structure and degree of inefficiency. Some authors like Kalirajan (1981), estimated stochastic frontiers to predict firm level efficiencies, and then regressed these predicted efficiencies upon firm specific variables (such as managerial experience, ownership characteristic and production conditions) in an attempt to explain variations in output between firms in an industry. To overcome inconsistencies in the assumptions regarding the independence of inefficiency effects in this two-stage estimation procedure, Kumbhakar et al. (1991) and Reifschneider and Stevenson (1991) proposed a single stage stochastic frontier in which the inefficiency effects $\left(u_{i}\right)$ are express as an explicit function of the vector of firm specific variables and a random error. Battese and Coelli (1995) proposed a model that imposed allocative efficiency, removes first order profit maximizing conditions and permits panel data. The Battese and Coelli (1995) model specification can be expressed as:

$$
Y_{i}=\exp \left(X_{i} \beta+\varepsilon_{i}\right)=\exp \left(X_{i} \beta+V_{i}-U_{i}\right) \quad \varepsilon_{i}=V_{i}-U_{i,} i=1, \ldots, N
$$

Where, $Y i$ is scalar output of the ith farm, $X_{i}$ is a vector of input quantities and $\beta$ is a vector of parameters to be estimated, exp is the exponential function, $V_{i}$ is the disturbance term assumed to be independent and symmetrically distributed $N\left(0, \sigma_{\mathrm{V}}{ }^{2}\right)$ and it captures the effects of random shocks outside the farmers control (e.g. weather, disease outbreaks, measurements errors, etc.), $U_{i}$ is a non-negative random variable associated with technical inefficiency in production and is assumed to be independently distributed as truncations of the $N\left(Z_{\mathrm{i}} \delta, \sigma_{\mathrm{U}}^{2}\right)$ distribution. Following Battese and Coelli (1995), $U_{i}$ can be represented as:

$$
U_{i}=Z_{i} \delta+W
$$

Where $Z_{i}$ is a $\mathrm{p} \times 1$ vector of variables which may influence the efficiency of the ith firm, $\delta$ is a $1 \mathrm{x} p$ vector of parameters to be estimated and $W_{i}$ is the random variable defined by the truncation of the normal distribution with mean 0 and variance $\sigma_{U}^{2}$.

Technical efficiency is defined as the ratio of the observed output $(\mathrm{Y})$ to the corresponding frontier output $\left(\mathrm{Y}^{*}\right)$ conditional on the levels of inputs used by the firm. In the context of the stochastic frontier production function Equation (1), technical efficiency is given by:

$$
T E=Y_{i} / Y_{i}^{*}=\exp \left(X_{i} \beta+V_{i}-U_{i}\right) / \exp \left(X_{i} \beta+V_{i}\right)=\exp \left(-U_{i}\right)
$$

Aigner et al. (1977) suggest using a likelihood function to allow for two variance parameters, $\sigma^{2}=\sigma_{\mathrm{U}}^{2}+\sigma_{\mathrm{V}}^{2}$ and $\lambda=\sigma_{U} / \sigma_{V}$ in the stochastic frontier production function. Values of $\gamma$ must lie between zero and one with values of 0 indicating the deviations from the frontier are entirely due to noise, and values of 1 indicating that all deviations are due to technical inefficiencies.

\section{Methodology}

\subsection{The Data and Sample}

The data for this study was obtained from a survey of maize farmers in Central Province, the third largest maize producing region in Zambia. Two districts Mumbwa and Chibombo were selected and the farms in the selected districts are similar in a number of ways; the technical and agronomic practice recommendation domains are similar and the districts are in close proximity to each other and as such, they face similar natural and market conditions.

The sampling methodology applied in the survey paralleled the national Central Statistical Office's (CSO) methodology. A two-stage cluster sampling process was used and CSO Standard Enumeration Areas (SEAs) were used as the primary sampling Units or clusters being selected with probability proportional to size (PPS). Individual households were then sampled using systematic probability sampling, following a comprehensive listing of all the households in the selected SEAs. Twenty households were randomly selected from 20 SEAs giving a total of 400 farming households.

Data was collected using a structured questionnaire, on farmers' output of maize, inputs used in the production process (land, capital, labor fertilizer and seeds) on each plot, and the socio-economic and plot-specific characteristics. These included farmer's age, level of education, household size and farm size, membership in cooperative and producer organizations as well as other relevant variables. These characteristics have been 
included in many studies of production. The reference period for this study was from November 2010 to August 2011.The variables used in this analysis are defined in Table 1.

Table 1. Variable definitions and measurement units for the empirical model

\begin{tabular}{cllcccc}
\hline Variable & \multicolumn{1}{c}{ Description } & \multicolumn{1}{c}{ Units } & Mean & Std. Dev. & Min & Max \\
\hline $\mathrm{Y}$ & Maize Output & $\mathrm{mt}$ & 3.32 & 7.69 & 0.00 & 120.75 \\
$\mathrm{X}_{1}$ & Chemical fertilizers used & $\mathrm{Kgs}$ & 271.87 & 801.78 & 0.00 & 1350.00 \\
$\mathrm{X}_{2}$ & Quantity of seed planted & $\mathrm{Kgs}$ & 41.45 & 55.38 & 1.00 & 627.00 \\
$\mathrm{X}_{3}$ & Farm size & $\mathrm{Ha}$ & 2.18 & 2.72 & 0.13 & 18.00 \\
$\mathrm{X}_{1}$ & Labor used in production & man hours & 62.41 & 55.65 & 30.00 & 330.00 \\
$\mathrm{Z}_{1}$ & Received credit & 1=yes, $0=\mathrm{No}$ & 0.07 & 0.25 & 0.00 & 1.00 \\
$\mathrm{Z}_{2}$ & Number of extension visits & ZMW & 1.86 & 2.80 & 0.00 & 7.00 \\
$\mathrm{Z}_{3}$ & Use of hybrid seed & 1=yes, $0=\mathrm{No}$ & 0.73 & 0.45 & 0.00 & 1.00 \\
$\mathrm{Z}_{4}$ & Member of an association & 1=yes, $0=\mathrm{No}$ & 0.35 & 0.48 & 0.00 & 1.00 \\
$\mathrm{Z}_{5}$ & Owns livestock & 1=yes, $0=\mathrm{No}$ & 0.36 & 0.48 & 0.00 & 1.00 \\
$\mathrm{Z}_{6}$ & Education of household head & years & 6.72 & 3.41 & 0.00 & 17.00 \\
$\mathrm{Z}_{7}$ & Age of household head & years & 46.91 & 15.03 & 19.00 & 95.00 \\
$\mathrm{Z}_{8}$ & Gender of household head & 1=male & 0.80 & 0.40 & 0.00 & 1.00 \\
$\mathrm{Z}_{9}$ & Total household income & ZMW & 3241 & 637 & 86 & 46000 \\
$\mathrm{Z}_{10}$ & Off farm income & ZMW & 2607 & 5944 & 0.00 & 43000 \\
\hline $\mathrm{Surv}$ & 2011. & & & &
\end{tabular}

Source: Field Survey, 2011.

The majority of farmers are males, with an average age of 47 years. The age of the household head is an important factor as it determines whether the household benefits from the experience of older farmers or the risk taking attitude of younger farmers. The average number of years in formal education is 7 years, which is primary education. The farming households in this study have an average household size of 6 members and an average of 3 prime age adults, i.e. adults between 19 and 59 years old. Only six percent of the households acquired formal loans and 34\% own large livestock.

In this planting season, farmers produced an average of 3.3 metric tons of maize with the largest producer producing 121 metric tons. The average farm size was 2.2 hectares and $41 \mathrm{~kg}$ of seed was used per household. Fertilizer application was minimal with an average of $272 \mathrm{kgs}$ of fertilizers being used per household against a mean land area of 2.2 hectares. Farmers used an average of 62 man-days to produce and harvest the maize, although there was a wide variation, ranging from 30 to 300 man-days.

\subsection{Empirical Model}

This study uses the stochastic frontier production function model which has the advantage that it allows for simultaneous estimation of individual technical efficiency of the respondent farmers as well as determinants of technical efficiency (Battese \& Coelli, 1995). Following Battese and Coelli (1983), technical efficiencies and their determinants were estimated using a one-step maximum likelihood estimates (MLE) procedure. This is done by incorporating the model for technical efficiency effects into the production function. This study specifies the stochastic frontier production function using the flexible translog specification and later carries out a log likelihood ratio test to determine if the translog reduces to Cobb-Douglas production function. The translog model is specified as follows:

$$
\begin{gathered}
\operatorname{Ln} Y=\beta_{0}+\beta_{1} \ln X_{1}+\beta_{2} \ln X_{2}+\beta_{3} \ln X_{3}+\beta_{4} \ln X_{4}+\beta_{11} \ln X_{1}^{2}+\beta_{22} \ln X_{2}^{2}+\beta_{33} \ln X_{3}^{2}+\beta_{44} \ln X_{4}^{2}+\beta_{12} \ln X_{1} \ln X_{2}+\beta_{13} \ln X_{1} \ln X_{3}+ \\
\beta_{14} \ln X_{1} \ln X_{4}+\beta_{23} \ln X_{2} \ln X_{3}+\beta_{24} \ln X_{2} \ln X_{4}+\beta_{34} \ln X_{3} \ln X_{4}+V-U
\end{gathered}
$$

Where, $\mathrm{Ln}$ is the natural logarithm, Y is output if ith farmer, X's are inputs variables presented in Table 1 and $\beta$ 's are parameters to be estimated. Maximum likelihood estimation of Equation (4), provides the estimators for $\beta$ 's 
and variance parameters $\sigma^{2}$ and $\gamma$. The inefficiency model is estimated from the Equation given below.

$$
U_{i}=\delta_{0}+\delta_{1} Z_{1}+\delta_{2} Z_{2}+\delta_{3} Z_{3}+\delta_{4} Z_{4}+\delta_{5} Z_{5}+\delta_{6} Z_{6}+\delta_{7} Z_{7}+\delta_{8} Z_{8}+\delta_{9} Z_{9}
$$

Where, Z's are various operational and farm specific variables described in Table 1 and $\delta_{i}$ 's are unknown parameters to be estimated.

\subsubsection{Testing Hypotheses}

It should be noted that technical inefficiency model in Equation (5) can only be estimated if the technical inefficiency effects, Ui's are stochastic and have particular distributional properties (Coelli \& Battese, 1996). It is therefore of interest to test the following hypotheses,

1) $\mathrm{H}_{0}: \gamma=\delta_{0}=\delta_{1}=\ldots=\delta_{9}=0$, the null hypothesis specifies that inefficiencies are absent from the model at every level;

2) $\mathrm{H}_{0}: \gamma=0$, the null hypothesis specifies that the inefficiencies are not stochastic;

3) $\mathrm{H}_{0}: \delta_{1}=\delta_{2}=\ldots=\delta_{9}=0$, the null hypothesis specifies that the inefficiency effects are not a linear function of each of the inefficiency factors and

4) $\mathrm{H}_{0}: \mu=0$, the null hypothesis specifies that each farm is operating on the technical efficient frontier and that the asymmetric and random technical efficiency in the inefficiency effects are zero

Under the null hypothesis, $\mathrm{H}_{0}: \gamma=0$; the stochastic frontier model reduces to a traditional average response function, without the technical inefficiency effect $U_{i}$. These and related null hypotheses can be tested using the generalized likelihood - ratio statistic, $\lambda$, given by:

$$
\lambda=-2\left[\ln \left\{L\left(H_{0}\right)\right\}-\ln \left\{L\left(H_{1}\right)\right\}\right]
$$

Where $\mathrm{L}\left(\mathrm{H}_{0}\right)$ and $\mathrm{L}\left(\mathrm{H}_{1}\right)$ denote the values of the likelihood function under the null $\left(\mathrm{H}_{0}\right)$ and alternative $\left(\mathrm{H}_{1}\right)$ hypotheses, respectively. If the given null hypothesis is true, $\lambda$ has approximately $\chi^{2}-$ distribution or mixed $\chi^{2}-$ distribution when the null hypothesis involves $\gamma=0$ (Coelli, 1995).

\subsubsection{Output Elasticities and Returns to Scale}

The first-order coefficients of the Trans log production function Equation (4) are not considered as they are not very informative, instead the determination of elasticities becomes necessary for the estimation of responsiveness of yield to inputs. Output elasticities for each of the inputs calculated at the variable means are of great importance in this case. (Awudu \& Eberlin, 2001).The elasticity of output with respect to the ith input, $\mathrm{e}_{\mathrm{i}}$, evaluated at the mean values of the relevant data points can be derived as:

$$
e_{i}=\frac{\partial \ln Y}{\partial \ln X_{i}}=\beta_{i}+2 \beta_{i i} \ln \bar{X}_{i}+\sum_{j \neq i} \beta_{i j} \ln \bar{X}_{j}
$$

Using Equation (4), output elasticity with respect to input, $X_{1}$ evaluated at the sample mean can thus be computed from the following Equation:

$$
e_{X_{1}}=\frac{\partial \ln Y}{\partial \ln X_{1}}=\beta_{1}+2 \beta_{11} \ln \bar{X}_{1}+\beta_{12} \ln \bar{X}_{2}+\beta_{13} \ln \bar{X}_{3}+\beta_{14} \ln \bar{X}_{4}
$$

The elasticity of output with respect to the ith input measures the responsiveness of output to a $1 \%$ change in the ith input. The measure of returns to scale, RTS representing the percentage change in output due to a proportional change in use of all inputs, is estimated as the sum of output elasticities for all inputs. If this estimate is greater than, equal to, or less than one, we have increasing, constant, or decreasing returns to scale respectively.

\section{Results and Discussions}

\subsection{Parameter Estimates}

The maximum likelihood estimates (MLE) of the parameters of stochastic frontier production function and the inefficiency model were simultaneously obtained using frontier in Stata. All summary statistics and regression reports in this paper were generated using the same software. Table 2 shows the MLE of parameters of the stochastic production frontier model and those of the technical inefficiency model.

Given the lack of direct interpretation of parameters in the translog production frontier, the parameter estimates of the stochastic production frontier Equation (4) will be summarized and explained later in terms of output elasticities with respect to various inputs. The $\gamma$ parameter associated with variances in the stochastic production frontier is estimated to be close to 1 (Table 2). Although the $\gamma$ - parameter cannot be interpreted as the proportion 
of the total variance explained by technical inefficiency effects, the results indicate that technical inefficiency effects do make a significant contribution to the level and variation of maize production in Central Province. Generalized likelihood-ratio test of various null hypotheses involving the restrictions on the variance parameter, $\gamma$, in the stochastic production frontier and $\delta$ - coefficient in the technical inefficiency model are presented in Table 3 .

Table 2 Parameter estimates of stochastic production frontier and technical inefficiency models

\begin{tabular}{llll}
\hline Variables & Parameter & Coefficient & Standard error \\
\hline Stochastic production Frontier & & & \\
Constant & $\beta_{0}$ & $8.138^{* * *}$ & 1.260 \\
LNFERT & $\beta_{1}$ & $0.526^{* * *}$ & 0.132 \\
LNSEED & $\beta_{2}$ & $0.122^{* * *}$ & 0.022 \\
LNFARM & $\beta_{3}$ & $1.040^{* * *}$ & 0.439 \\
LNLABOR & $\beta_{4}$ & -0.044 & 0.039 \\
LNFERTSQ & $\beta_{11}$ & $0.117^{* * *}$ & 0.021 \\
LNSEEDSQ & $\beta_{22}$ & $0.044^{* *}$ & 0.041 \\
LNFARMSQ & $\beta_{33}$ & -0.016 & 0.062 \\
LNLABORSQ & $\beta_{44}$ & -0.002 & 0.039 \\
LNFERTLNSEED & $\beta_{12}$ & $-0.030^{* * *}$ & 0.0392 \\
LNFERTLNFARM & $\beta_{13}$ & $-0.017^{*}$ & 0.0380 \\
LNFERTLNLABOR & $\beta_{14}$ & $0.020^{* *}$ & 0.0273 \\
LNSEEDLNFARM & $\beta_{23}$ & -0.075 & 0.0838 \\
LNLABORLNFARM & $\beta_{24}$ & $-0.225^{* * *}$ & 0.0794 \\
LNSEEDLNLABOR & $\beta_{34}$ & $0.139^{* *}$ & 0.0921
\end{tabular}

Technical Inefficiency Model

Constant

$\begin{array}{lll}\delta_{0} & 0.075^{* *} & 0.032\end{array}$

Received credit (1=yes)

$1.060 * * * \quad 0.508$

Number of extension visits

$\delta_{1}$

$0.070 * * \quad 0.044$

Used hybrid seed (1=yes)

$\delta_{2}$

$1.478 * * * \quad 0.284$

Belongs to an Association (1=yes)

$\delta_{3}$

0.576

0.316

Owns livestock ( $1=$ yes $)$

$0.117 \quad 0.454$

Education of household head

0.007

0.037

Age of household head

$\delta_{5}$

$0.012 * * \quad 0.008$

Total Household income

$-0.020 * * \quad 0.000$

Off farm income

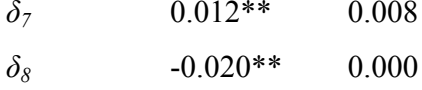

$\begin{array}{lll}\delta_{9} & 0.003^{* *} & 0.000\end{array}$

Variance parameters

$\begin{array}{llll}\text { Sigma squared } & \sigma^{2} & 0.25^{* *} & 0166 \\ \text { Gamma, }\left(\sigma_{u}{ }^{2} /\left(\sigma_{\mathrm{u}}{ }^{2}+{\sigma_{\mathrm{v}}}^{2}\right)\right. & \gamma & 0.898^{* *} & \\ \text { Ln (likelihood) } & & -436.571 & \\ \text { Mean technical efficiency } & & 0.507 & 0.174\end{array}$

$* * * \mathrm{p}<0.01, * * \mathrm{p}<0.05, * \mathrm{p}<0.1$. 


\subsection{Hypothesis Testing}

A likelihood test was conducted to test the null hypothesis that the translog stochastic frontier production function can be reduced to a Cobb Douglas. The test statistic $\mathrm{H}_{0}: \beta \mathrm{ij}=0, \mathrm{H}_{0}: \beta_{\mathrm{ij}} \neq 0$, as shown in Table 3 has a likelihood ratio value of 47.5 , which implies a reject of the null hypothesis at $1 \%$ significance. In other words, the translog model does not reduce to a Cobb Douglas model and is hence the ideal model.

Testing the model specification for technical inefficiency in Table 3 shows that both null hypotheses that the technical inefficiency effects are absent (hypothesis 1) and that inefficiency effects are not stochastic (hypothesis 2) are rejected, which implies that the traditional production function is not an adequate representation of maize production data used in this study. In this case, it is can be said that inefficiencies are present and they are stochastic. The third null hypothesis determines whether the variables included in the inefficiency effects model have no effect on the level of technical inefficiency. $\mathrm{H}_{0}: \delta_{0}=\delta_{1}=\ldots=\delta_{9}=0$, the null hypothesis is rejected confirming that the joint effect of these variables on technical inefficiency is statistically significant. The final null hypothesis explores the test that specifies each farm is operating on the technically efficient frontier and that the systematic and random technical efficiency in the inefficiency effects are zero. This is rejected in favor of the presence of inefficiency effects.

Table 3. Hypothesis tests for model specification and statistical assumptions

\begin{tabular}{lcccc}
\hline Null Hypothesis & Likelihood Ratio test (LR) & df & P-value & Decision \\
\hline \multicolumn{2}{l}{ Testing the null hypothesis that translog model can be reduced to Cobb Douglas model } & \\
$\mathrm{H}_{0}: \beta_{\mathrm{ij}}=0$ & 47.48 & 10 & 0.000 & Reject Ho \\
Testing the specification of technical inefficiency model & & & \\
(1) $\mathrm{H}_{0}: \gamma=\delta_{0}=\delta_{1}=\ldots=\delta_{9}=0$ & 62.73 & 12 & 0.000 & Reject Ho \\
(2) $\mathrm{H}_{0}: \gamma=0$ & 13.24 & 1 & 0.000 & Reject Ho \\
(3) $\mathrm{H}_{0}: \delta_{0}=\delta_{1}=\ldots=\delta_{9}=0$ & 53.33 & 10 & 0.000 & Reject Ho \\
(4) $\mathrm{H} 0: \mu=0$ & 18.64 & 1 & 0.000 & Reject Ho \\
\hline
\end{tabular}

\subsection{Output Elasticities and Returns to Scale}

The estimates of output elasticities evaluated at means of relevant data points and defined by Equation (7) are represented in Table 4. As expected, the estimated values of output elasticities for all inputs are positive. Furthermore all elasticities are significantly different from zero at the 0.1 levels of significance. Fertilizer is found to have the highest elasticity $(0.76)$, followed by seed $(0.54)$ and labor $(0.46)$.

Table 4. Output elasticities

\begin{tabular}{ll}
\hline Input variable & elasticity \\
\hline Fertiliser & $0.763^{*}$ \\
Seed & $0.545^{* *}$ \\
Farm size & $0.399^{* *}$ \\
Labour & $0.457^{*}$ \\
\hline
\end{tabular}

$* * * \mathrm{p}<0.01, * * \mathrm{p}<0.05, * \mathrm{p}<0 . \overline{1 .}$

The returns to scale computed as the sum of output elasticities for all inputs is estimated as 2.164 , indicating that on average the maize production has increasing returns to scale. Put another way, if the farmers increased all factors by $1 \%$, maize production would increase by $2.16 \%$, and farmers would profit financially.

\subsection{Technical Efficiency}

The mean technical efficiency scores was 50\% and ranged between 2.2 and $84.5 \%$ (Table 5). These technical efficiency results are comparable to those revealed by Kibaara (2005) in Kenya where technical efficiency was at $49 \%$ and Chirwa (2007) in Malawi where technical efficiency was at $46 \%$. There is tremendous opportunity to 
improve technical efficiency among the farmers in that it is possible to increase production by $50 \%$ from the current level of technology and input use.

Table 5. Technical efficiency by districts

\begin{tabular}{llll}
\hline Statistic & Chibombo & Mumbwa & Overall \\
\hline Mean & 0.491 & 0.523 & 0.507 \\
Std dev. & 0.174 & 0.173 & 0.174 \\
Min & 0.070 & 0.022 & 0.022 \\
Max & 0.840 & 0.845 & 0.845 \\
\hline
\end{tabular}

Source: Field Survey, 2011.

Despite the two districts being in close proximity and facing similar natural and market condition, there is some slight variation in efficiency between the farmers in the two districts. Mumbwa is observed to have a higher technical efficiency compared to Chibombo. The differences can be attributed to farm and farmers characteristics which are expected to vary from household to household and hence from district to district.

Table 6. Distribution of farmers' specific technical efficiencies

\begin{tabular}{cccc}
\hline Efficiency & Number of farmers & Percentage & Cumulative Percentage \\
\hline$<10$ & 3 & 0.75 & 0.75 \\
$10-10.99$ & 19 & 4.75 & 5.50 \\
$20-20.99$ & 36 & 9.00 & 14.50 \\
$30-30.99$ & 54 & 13.50 & 28.00 \\
$40-40.99$ & 71 & 17.75 & 45.75 \\
$50-50.99$ & 71 & 17.75 & 63.50 \\
$60-60.99$ & 91 & 22.75 & 86.25 \\
$70-70.99$ & 47 & 12.25 & 98.50 \\
$80-80.99$ & 4 & 1.00 & 99.50 \\
$90-100$ & 2 & 0.50 & 100.00 \\
\hline Total & 400 & 100.00 & \\
\hline
\end{tabular}

Source: Field Survey, 2011.

The distribution of technical efficiency across the 400 maize farmers is fairly normal. Table 6 shows that $14.5 \%$ of the farmers have efficiency scores that are less than $30 \%$ and $45.75 \%$ of the farmers have technical scores above $50 \%$ with only $13.75 \%$ having technical efficiency scores above $70 \%$.

\subsubsection{Factors Affecting Technical Efficiency}

The inefficiency model in Table 3 gives some insights on factors affecting technical efficiency. A negative sign on a parameter means that the variable reduces technical efficiency while a positive sign increases technical efficiency. The survey revealed that six main determinants were associated with technical efficiency in the sampled maize farmers. These include, age of farmer, use of hybrid seed, number of extension visits and access to credit, years of formal education and off-farm income.

Access to credit addresses the problem of liquidity and enhances use of agricultural inputs in production, as it is often claimed in development theory. In this study, access to credit, was observed to significantly influence technical efficiency in the positive sense. Farmers with access to credit are better able to access expensive efficiency enhancing technologies like hybrid seed and fertilizer. Similar results were observed by Desai and Mellor (1993) and Nwagbo (1989) who argued that farm level credit when properly extended encourages diversified agriculture which stabilizes and perhaps increases resource productivity, agricultural production, 
value added, net farm incomes and therefore facilitates adoption of innovations in farming, encouraging capital formation and marketing efficiency.

Another important variable in efficiency is access to extension services represented by the number of extension visits received by the farmer. Farmers who had access to more extension services either in form of literature or contact exhibited improved efficiency. This could be because such farmers have easier access to market information and best available practices from which they can make informed market choices and adopt efficiency enhancing technologies

Farmers have various options before them on what type of seed to use, subject to the constraints they face. In this study, farmers used mainly either hybrid seed or local and recycled hybrid seed. A comparison between those using hybrid and local or recycled hybrid seed suggests that farmers using certified hybrid seed are observed to have higher technical efficiency compared to those using recycled and local seed.

The age of a household head is observed to have a positive coefficient indicating that older farmers are more technically efficient than older ones. Wozniak (1987) observed similar results and argued that the older the farmer, the more experienced he/she will be. Besides, given the importance and significance of land, labor, capital and other resources in farm production, it could be argued that young households are deficient in resources and might not be able to apply inputs or implement certain agronomic practices sufficiently quickly. As timely application of inputs and implementation of management is expected to enhance efficiency, young farmers may find this challenging.

Finally, in this study off-farm income is observed to diminish technical efficiency. It can be hypothesized that managerial input may be withdrawn from farming activities with increased participation of the educated in non-farm activities, which leads to lower efficiency. Similarly, Abdulai and Eberlin (2001) found higher inefficiency of production with involvement of households in non-farm activities. This could be because farmers who have various sources of income beside crop production are more likely to be preoccupied with other income generating activities and hence pay less attention to important agronomical practices. In such instances, labor contributions to on-farm operations is negatively affected and this affects efficiency negatively. On the contrary, total household income affects technical efficiency positively. The difference between off-farm income and total household income is the value of crop sales. This implies that farmers with higher proportions of total household income from crop sales have higher technical efficiency. Such farmers are likely to concentrate more on crop production and invest in efficiency enhancing technologies. For both off-farm and total incomes, the effects are highly significant but the magnitude of the effect is very minimal if not negligible.

\section{Conclusions and Recommendations}

This study set out to estimate the technical efficiency and also determine socio-economic and farm specific factors that influence technical efficiency in maize production among smallholder farmers in Zambia. The study results show that mean technical efficiency scores were $50 \%$ and ranged between 2.2 and $84.5 \%$. This suggests tremendous opportunity to improve technical efficiency among the farmers. The distribution of the farm level measures of technical efficiency shows that $14.5 \%$ of the farmers have efficiency scores that are less than $30 \%$ and $45.75 \%$ of the farmers have technical scores above $50 \%$ with only $13.75 \%$ having technical efficiency scores above 70 . Farmers who are older, use hybrid seed, accessed credit and receive more extension visits exhibit higher efficiency scores.

Despite continued government investment in the agriculture sector through agricultural input subsides, extension services and promotion of new technology, small scale maize farming has remained technically inefficient. Three policy issues emerge from the results of this study. Firstly, given the positive effect of certified hybrid seed on efficiency, it is important to continue promoting use of hybrid seed among maize farmers. Secondly, given the positive effect of access to finance and extension services on technical efficiency, it is therefore of great importance that the agricultural development strategy focuses on creating an environment that facilitates farmers' accessibility to better extension provisions and improved access to rural finance. There is available evidence that suggests that investment in public goods such as agricultural research, extension and roads constitutes one of the most effective tools available for stimulating economic growth and poverty reduction.

\section{Acknowledgements}

We would like to thank the African Economic Research Consortium (AERC) for funding this research project.

\section{References}

Abdulai, A., \& Eberlin, R. (2001). Technical efficiency during economic reform in Nicaragua: evidence from farm household survey data. Economic Systems, 25, 113-125. 
http://dx.doi.org/10.1016/s0939-3625(01)00010-3

Abdulai, A., \& Huffman, W. E. (2000). Structural adjustment and economic efficiency of rice farmers in Northern Ghana. Economic Development and Cultural Change, 48(3), 503-520. http://dx.doi.org/10.1086/452608

Agriculture Consultative Forum. (2009). Report on the Proposed Reforms for the Zambia Fertilizer Support Program. Lusaka Zambia.

Aigner, D. J., \& Chu, S. F. (1968). On estimating the industry production function. Am. Econ. Rev., 58(4), 826-839.

Aigner, D. J., Lovell, C. A. K., \& Schmidt, P. (1977). Formulation and estimation of stochastic frontier production models. J. Econ., 6, 21-37. http://dx.doi.org/10.1016/0304-4076(77)90052-5

Ajibefun, I. A. (2008). An Evaluation of Parametric and Non Parametric Methods of Technical Efficiency Measurement: Application to Smallholder Crop Production in Nigeria. Journal of Agriculture and Social Sciences. 4, 95-100. Retrieved from http://www.fspublishers.org/published_papers/70167_...pdf

Awudu, A., \& Eberlin, R., (2001). Technical efficiency during economic reform in Nicaragua: evidence from farm household survey data. Economic Systems, 15(25), 113-125. http://dx.doi.org/10.1016/s0939-3625 (01)00010-3

Battese, G. E., \& Coelli, T. J. (1995). A model for technical inefficiency effect in stochastic frontier production for panel data. Empirical Economics, 20, 325-332. http://dx.doi.org/10.1007/bf01205442

Battese, G. E., \& Cora, G. S. (1977). Estimation of production function model with application to the pastoral zone of eastern Australia. Aus. J. Agric. Econ., 21, 169-179. http://dx.doi.org/10.1111/j.1467-8489.1977.tb00204.x

Chirwa, E. W. (2007). Sources of Technical Efficiency among Small holder Maize Farmers in Southern Malawi. AERC Research Paper 172. African Economic Research Consortium, Nairobi, Kenya. Retrieved from http://www.ndr.mw:8080/xmlui/bitstream/handle/123456789/324/Sources\%20of\%20technical\%20efficienc y\%20among\%20smallholders\%20maize \%20farmers.pdf?sequence $=1$

Desai, B. M., \& Mellor, J. W. (1993). Institutional Finance for Agricultural Development: An Analytical Survey of Critical Issues (Food Policy Review 1). Washington: International Food Policy Research Institute.

Feder, G., Just, R. E., \& Zilberman, D. (1985). Adoption of Agricultural Innovations in Developing Countries: A survey. Economic Development and Cultural Change, 33(2), 255-298. http://dx.doi.org/10.1086/451461

Food and Agriculture Organization (FAO). (2011). FAO Stat. Retrieved January 12, 2014, from http://faostat.fao.org/site/291/default.aspx

Farrell, M. J. (1957). The Measurement of Productive Efficiency. Journal of the Royal Statistical Society. Series A (General), 120(3), 253-290. http://dx.doi.org/10.2307/2343100

Hussain S. S. (1989). Analysis of Economic Efficiency in Northern Pakistan: Estimation, Causes and Policy Implications. Ph.D. diss., University of Illinois.

Jayne, T. S., Mason, N., Myers, R., Ferris, J., Mather, D., Beaver, M., ... Boughton, D. (2010). Patterns and Trends in Food Staples Markets in Eastern and Southern Africa: Toward the Identification of Priority Investments and Strategies for Developing Markets and Promoting Smallholder Productivity Growth. International Development Working Paper 104. East Lansing, MI, US: Michigan State University. Retrieved from http://fsg.afre.msu.edu/papers/idwp104.pdf

Jondrow, J., Lovell, C. A. K., Materov, T. S., \& Schmidt, P. (1982). On the estimating of technical inefficiency in the stochastic frontier production model. Journal of Econometrics, 19, 233-238. http://dx.doi.org/10.1016/0304-4076 (82)90004-5

Kalirajan, K. (1981). An Econometric Analysis of Yield Variability in Paddy Production. Canadian Journal of Agricultural Economics, 29, 283-294. http://dx.doi.org/10.1111/j.1744-7976.1981.tb02083.x

Kalirajan, K. P., \& Flinn, J. C. (1983). The measurement of farm specific technical efficiency. Pakistan J. Applied Econ, 2, 167-180.

Kibaara, B. W. (2005). Technical Efficiency in Kenyan's Maize Production: An Application of the Stochastic Frontier Approach. Master of Science Thesis, Colorado State University. Retrieved from http://fsg.afre.msu.edu/kenya/o_papers/tech_eff_maize.pdf 
Kumar, S. K. (1994). Adoption of Hybrid Maize in Zambia: Effects on Gender Roles, Food Consumption, and Nutrition. Research Report 100. Washington, DC: International Food Policy Research Institute. Retrieved from http://www.ifpri.org/sites/default/files/publications/rr100.pdf

Kumbhakar, S. C., Ghosh, S., \& McGuckin, J. T. (1991). A Generalized Production Frontier Approach for Estimating Determinants of Inefficiency in U.S. Dairy Farms. Journal of Business and Economic Statistics, 9, 279-286. http://dx.doi.org/10.1080/07350015.1991.10509853

Meeusen, W., \& Van den Broeck, J. (1977). Efficiency Estimation from Cobb - Douglas Production Functions with Composed Error. International Economic Review, 18, 435-444. http://dx.doi.org/10.2307/2525757

Ministry of Agriculture and Cooperatives, Central Statistics Office, Food Security Project. (2008). Patterns of Maize Farming Behavior and Performance among Small and Medium Scale Smallholders in Zambia. $\mathrm{MACO} / \mathrm{CSO} / \mathrm{FSP}$ Lusaka. Retrieved from http://fsg.afre.msu.edu/zambia/MACO_CSO_FSRP_CFS_new_version_June20.pdf

Nwagbo, E. C. (1989). Impact of Institutional Credit on Agriculture in Funtua Local Government area of Katsina State, Nigeria. Samaru J. Agric. Res., 6, 75-86.

Ogundari, K., \& Ojo, S. O. (2008). The Determinants of Technical Efficiency in Mixed Crop Food Production in Nigeria: A Stochastic Parametric Approach. Eastern Africa Journal of Rural Development, 21(1). http://dx.doi.org/10.4314/eajrd.v21i1.28368

Pender, J., Nkonya, E., Jagger, P., Sserunkuuma, D., \& Ssali, H. (2004). Strategies to Increase Agricultural Productivity and Reduce Land Degradation: Evidence from Uganda. Agricultural Economics, 31(2/3), 181-195. http://dx.doi.org/10.1016/j.agecon.2004.09.006

Reifschneider, D., \& Stevenson, R. (1991). Systematic departures from the frontier: a framework for the analysis of firm inefficiency. International Economic Review, 32, 715-723. http://dx.doi.org/10.2307/2527115

Shafiq, M., \& Rehman, T. (2000). The Extent of Resource use Inefficiencies in Cotton Production in Pakistan's Punjab: An Application of Data Envelopment Analysis. Agricultural Economics, 22, 321-330. http://dx.doi.org/10.1111/j.1574-0862.2000.tb00078.x

Wozniak, G. (1987). Human Capital, Information, and the Early Adoption of New Technology. Journal of Human Resources, 22(1), 101-12. http://dx.doi.org/10.2307/145869

Wilson, P., Hadley, D., \& Ashby, C. (2001). The Influence of Management Characteristics on the Technical Efficiency of Wheat Farmers in Eastern England. Agricultural Economics, 24, 329-338. http://dx.doi.org/10.1111/j.1574-0862.2001.tb00034.x

Xu, Z., Guan, Z., Jayne, T. S., \& Black, R. (2009). Factors Influencing the Profitability of Fertilizer use on Maize in Zambia. Agricultural Economics, 40(4), 437-446. http://dx.doi.org/10.1111/j.1574-0862.2009.00384.x

Zulu, B., Jayne, T. S., \& Beaver, M. (2007). Smallholder Maize Production and Marketing Behavior in Zambia and its Implications for Policy. Working Paper No. 22 Food Security Research Project, Lusaka, Zambia. Retrieved from http://fsg.afre.msu.edu/zambia/wp_22.pdf

\section{Copyrights}

Copyright for this article is retained by the author(s), with first publication rights granted to the journal.

This is an open-access article distributed under the terms and conditions of the Creative Commons Attribution license (http://creativecommons.org/licenses/by/3.0/). 